\title{
Lipid and apolipoprotein B48 transport in mesenteric lymph and the effect of hyperphagia on the clearance of chylomicron-like emulsions in insulin-deficient rats
}

\author{
I.J. Martins, A. J.Sainsbury, J. C. L. Mamo, T. G. Redgrave \\ Department of Physiology, The University of Western Australia, Nedlands, Australia
}

Summary In insulin-deficient streptozotocin-treated rats the intestine is hypertrophic and cholesterol synthesis and transport from the intestine are increased. The increased load of cholesterol is transported through the mesenteric lymph in chylomicrons. Clearance from plasma of injected chylomicrons is slowed in insulin-deficient rats, but the underlying mechanisms are currently unresolved. Hyperphagia may increase the size of chylomicrons which could contribute to defective chylomicron clearance in insulin-deficiency. In the present experiments we compared the size and number of chylomicrons in mesenteric lymph of control rats and diabetic rats infused with fat at two levels. In control and diabetic lymph-cannulated rats, as the infused dose of lipid increased the transport of triglyceride increased substantially compared with fasted rats. In contrast the transport of apoB48 increased by only a small amount during fat transport. Therefore, increased lipid transport was accomplished mostly by in- creased particle size, with only small increases in numbers of particles in intestinal lymph. Insulin-deficiency had no effect on triglyceride or apoB48 transport in lymph. Calculations suggested that each chylomicron particle contained a single molecule of apoB 48 . When hyperphagia in diabetic rats was prevented, the plasma triglycerides were decreased but the slow plasma clearance of injected chylomicron-like emulsions persisted. Hyperphagia, therefore, was unconnected to the impairment in chylomicron metabolism in insulin-deficient rats. Changes in the association with plasma apolipoproteins, in the expression of receptors for uptake of chylomicron remnants or in exposure to endothelial lipases may be responsible for the defective clearance of triacylglycerol-rich lipoproteins. [Diabetologia (1994) 37: 238-246]

Key words Chylomicrons, chylomicron remnants, intestine, diabetes mellitus, apolipoprotein B48.
The majority of dietary triglycerides and cholesterol, together with lipids from bile, are transported after their digestion and absorption from the intestine by means of the mesenteric lymph. Transport is principally in the form of triglyceride-rich particles, the lymph chylomicrons, composed mostly of lipids but also containing a number of different apolipoproteins.

Received: 3 May 1993

and in revised form: 27 September 1993

Corresponding author: Dr. I.J.Martins, Department of Physiology, The University of Western Australia, Stirling Highway, Nedlands Perth, Australia 6009

Abbreviations: Apo, Apolipoprotein.
The largest of these proteins, apoB $48(241 \mathrm{kDa})$, is synthesized in the intestine from the apoB gene by an mRNA editing mechanism so that apoB 48 consists of the amino-terminal 2152 residues of apoB100 [1-3]. In man the liver makes apoB100, while the intestine makes apoB48 and small quantities of apoB100 $[4,5]$. In the rat the liver makes apoB 48 and $\mathrm{B} 100$, while the intestine makes only apoB48 [6]. ApoB48 lacks the domain required for binding of apoB 100 to the $\mathrm{LDL}$ receptor (i.e. the apoB100/E receptor). Consequently there is an absolute requirement for apoE to mediate the uptake of chylomicron remnant particles by LDL receptors [7].

Insulin deficiency is associated with multiple changes in lipid transport, including the transport of dietary lipids from the intestine. Possible mechanisms 
include changes in the size or numbers of chylomicrons produced by the intestine, or changes in the lipid composition of the particles. In diabetes the input of cholesterol from the intestine is increased [8]. There is increased absorption of dietary cholesterol [9] and increased synthesis of cholesterol by the intestine $[10$, 11]. The activity of the enzyme acylcoenzyme A:cholesterol acyltransferase in the intestine is also increased in streptozotocin-treated rats $[12,13]$. Associated with hyperphagia, the intestine becomes hypertrophic in diabetes [11], contributing to the increased cholesterol synthesis and raising the possibility that biosynthesis of apolipoproteins also increases. In the streptozotocintreated diabetic rat the clearance of chylomicrons from plasma is impaired [14]. The mechanism underlying this effect has not been established. In conjunction with defective clearance from blood of chylomicron remnants [14], the increased influx of cholesterol from the intestine seems likely to contribute to the increased atherogenesis of diabetes.

The assembly of triglyceride-rich lipoproteins within enterocytes and hepatocytes probably incorporates apoB in a quantum fashion, meaning that measurements of apoB correlate directly with the numbers of particles. Previous data indicated that two molecules of apoB48 may be present in chylomicrons, but the calculations depended on several assumptions and one molecule per particle was probably within the error of the methods available at that time [15]. Analogous studies with hepatic VLDL showed that each particle contained a single molecule of apoB100 [16].

The increased transport of fat after digestion and absorption of a dietary fat load could be accommodated by increasing the size of chylomicron particles, or by increasing the number of particles, or both. If more particles were produced this would be reflected in an increased mass of apoB48 in the lymph. Biosynthesis of apoB48 in rat intestinal mucosa was not increased during absorption of a fat load, but was decreased by diversion of bile [17]. Biosynthesis was maintained by replacement of bile salts, suggesting regulation by a steroid responsive element of the apoB gene. Neither fat absorption nor bile diversion significantly affected jejunal apoB48 synthesis in piglets [18]. In rats the apoB output in whole lymph and in the triglyceriderich lipoprotein fractions of lymph did not change from fasting values during the absorption of a triolein emulsion [19], supporting increased chylomicron size as the main mechanism for transport of a postprandial lipid load.

In the present experiments the effects of insulindeficiency and lipid transport on the numbers and size of particles in intestinal lymph have been estimated. We compared the transport of lipids and apoB48 in triglyceride-rich lipoproteins of lymph in normal and insulin-deficient rats. The effects of increasing fat loads, with and without added cholesterol, were also assessed. Hyperphagia in insulin-deficiency leads to an increased load of transported fat, with unknown effects on the capacity for chylomicron clearance. To assess the potential contribution of hyperphagia in insulindeficiency, the clearance of chylomicron-like emulsions was compared in diabetic rats consuming food freely, with others restricted to the food intake of paired non-diabetic control rats.

\section{Materials and methods}

\section{Animals}

For lymph studies male Wistar rats weighing approximately $300 \mathrm{~g}$ were obtained from the Animal Resources Centre (Murdoch, Western Australia) and fed a commercial rat pelleted diet containing approximately $5 \%$ fat. Rats were made insulin-deficient by intravenous injection of streptozotocin $50 \mathrm{mg} / \mathrm{kg}$ body weight dissolved in $0.01 \mathrm{~mol} / 1$ citrate buffer, $\mathrm{pH} 4.0$. Control rats were injected with buffer only. At 21 days after injection, control and insulin-deficient rats were anaesthetized and intestinal lymph was collected via a plastic tube surgically implanted in the principal mesenteric lymph duct. After surgery the rats were placed in individual cages to recover from anaesthesia and kept hydrated by a steady intragastric injection of $0.15 \mathrm{~mol} / / \mathrm{NaCl}$ at $2.0 \mathrm{ml} / \mathrm{h}$ through a gastrostomy tube placed at the time of lymph cannulation. Tap water was freely available to the rats.

For clearance studies male rats weighing $180-200 \mathrm{~g}$ were injected with streptozotocin as above, then divided into groups that were either allowed free access to the usual pelletted diet, or housed in individual cages and fed $20 \mathrm{~g}$ of crushed diet each day in broad-rimmed containers designed to prevent food spillage. Control non-diabetic rats with free access to food consumed $20.2 \pm 0.6 \mathrm{~g} /$ day. At least 3 weeks from the date of injection of streptozotocin, all rats were prepared surgically with arterial and venous cannulas as described earlier [14]. Lipid emulsions of similar size and composition to lymph chylomicrons and labelled with trace amounts of radioactive triolein and cholesteryl oleate were prepared and injected to measure plasma clearance exactly as described previously [14].

\section{Preparation of chylomicrons}

On the first post-operative day, lymph was collected for $4 \mathrm{~h}$ while rats received a steady intestinal infusion through the gastrostomy tube of $0.15 \mathrm{~mol} / 1 \mathrm{NaCl}$ containing either no Intralipid or Intralipid at triglyceride concentrations of either $25 \mathrm{mg} / \mathrm{h}$ or $125 \mathrm{mg} / \mathrm{h}$. Other groups of rats were infused in parallel with Intralipid containing $2 \%$ cholesterol. The infusion time of Intralipid (with or without cholesterol) was $6 \mathrm{~h}$. Beginning $2 \mathrm{~h}$ after the start of Intralipid infusion, lymph was collected for $4 \mathrm{~h}$ into vessels containing EDTA, gentamycin, reduced glutathione, aprotinin and phenylmethylsulphonyl fluoride $(0.3 \mathrm{~g} / \mathrm{ml}$ in dimethylsulphoxide) to final concentrations of $1 \mathrm{mg} / \mathrm{ml}$, $0.1 \mathrm{mg} / \mathrm{ml}, 1.6 \mathrm{mmol} / \mathrm{l}, 10 \mathrm{kallikrein} \mathrm{units} / \mathrm{ml}$ and $0.15 \%$ (w/v) respectively. Cells were removed by low speed centrifugation, then solid $\mathrm{KBr}$ was added $(1.96 \mathrm{~g} / 14 \mathrm{ml})$ to increase the density to $1.1 \mathrm{~g} / \mathrm{ml}$. After degassing in vacuo, $14 \mathrm{ml}$ of lymph was injected under discontinuous density gradients [20] consisting of $6 \mathrm{ml}$ solutions with densities $1.065,1.040,1.020$ and $1.006 \mathrm{~g} / \mathrm{ml}$. The gradients were then centrifuged at $20^{\circ} \mathrm{C}$ in the SW 28 rotor of the Beckman L8-M ultracentrifuge for $15 \mathrm{~h}$ at $28000 \mathrm{rev} / \mathrm{min}$. The triglyceride-rich lymph lipoproteins were removed from the top 
Table 1. The composition, size and volume of triglyceride-rich lipoproteins and the rates of transport of triglyceride and apoB48 in mesenteric lymph from control and diabetic rats fasted or infused with Intralipid at two doses with and without cholesterol

\begin{tabular}{|c|c|c|c|c|c|c|c|}
\hline \multicolumn{5}{|c|}{ Composition of triglyceride-rich lipoproteins ( $\%$ by weight) } & \multirow{2}{*}{$\begin{array}{l}\text { Diameter }^{\mathrm{a}} \\
\text { (nm) } \\
\text { (volume, } \\
\left.\mathrm{nm}^{3}\right)\end{array}$} & \multicolumn{2}{|c|}{ Lymph transport } \\
\hline $\begin{array}{l}\text { Triglyc- } \\
\text { erides }\end{array}$ & $\begin{array}{l}\text { Cholesterol } \\
\text { esters }\end{array}$ & $\begin{array}{l}\text { Phos- } \\
\text { pholipids }\end{array}$ & $\begin{array}{l}\text { Choles- } \\
\text { terol }\end{array}$ & $\begin{array}{l}\text { Total } \\
\text { protein }\end{array}$ & & $\begin{array}{l}\text { Triglyc- } \\
\text { erides } \\
\text { (mg/h) }\end{array}$ & $\begin{array}{l}\mathrm{B} 48 \\
(\mu \mathrm{g} / \mathrm{h})\end{array}$ \\
\hline
\end{tabular}

\begin{tabular}{|c|c|c|c|c|c|c|c|c|}
\hline \multicolumn{9}{|l|}{ Fasted } \\
\hline Control (10) & $64.0 \pm 2.21$ & $5.5 \pm 1.08$ & $22.7 \pm 0.86$ & $1.5 \pm 0.20$ & $6.2 \pm 0.74$ & $40(33510)$ & $6.5 \pm 1.42$ & $53.6 \pm 16.11$ \\
\hline Diabetic (8) & $68.9 \pm 0.82$ & $2.7 \pm 0.25$ & $22.2 \pm 0.69$ & $1.2 \pm 0.14$ & $4.9 \pm 0.52$ & $44(44602)$ & $6.5 \pm 0.69$ & $57.0 \pm 5.36$ \\
\hline \multicolumn{9}{|c|}{ Low dose Intralipid } \\
\hline Control (4) & $77.9 \pm 3.25$ & $2.1 \pm 0.72$ & $17.1 \pm 2.37$ & $0.6 \pm 0.21$ & $2.4 \pm 0.32$ & $62(124788)$ & $25.4 \pm 5.58$ & $78.0 \pm 12.50$ \\
\hline Diabetic (4) & $77.4 \pm 1.41$ & $1.5 \pm 0.39$ & $17.9 \pm 0.96$ & $0.5 \pm 0.12$ & $2.7 \pm 0.29$ & $60(113097)$ & $17.8 \pm 2.15$ & $62.8 \pm 7.72$ \\
\hline \multicolumn{9}{|c|}{ With cholesterol } \\
\hline Control (4) & $81.5 \pm 0.79$ & $3.2 \pm 0.21$ & $12.2 \pm 0.77$ & $1.0 \pm 0.05$ & $2.1 \pm 0.20$ & $86(333038)$ & $25.7 \pm 5.03$ & $81.9 \pm 15.70$ \\
\hline Diabetic (4) & $79.9 \pm 3.29$ & $2.6 \pm 0.42$ & $13.7 \pm 2.35$ & $0.7 \pm 0.13$ & $3.1 \pm 0.76$ & $74(212175)$ & $18.8 \pm 2.95$ & $72.8 \pm 12.29$ \\
\hline \multicolumn{9}{|c|}{ High dose Intralipid } \\
\hline Control (17) & $85.9 \pm 0.53$ & $0.8 \pm 0.07$ & 11.6 & 0.4 & $1.4 \pm$ & 247) & $37.5 \pm 3.65$ & 72. \\
\hline Diabetic (4) & $84.0 \pm 1.62$ & $0.8 \pm 0.12$ & $13.4 \pm 1.84$ & $0.4 \pm 0.09$ & $1.6 \pm 0.10$ & $84(310339)$ & $47.0 \pm 4.72$ & $91.6 \pm 14.02$ \\
\hline \multicolumn{9}{|c|}{ With cholesterol } \\
\hline & $87.9 \pm 0.30$ & $1.2 \pm 0.09$ & $9.2 \pm 0.29$ & $0.5 \pm 0$ & $1.1 \pm 0.09$ & $122(950776)$ & $45.0 \pm 2.09$ & $72.7 \pm 6.20$ \\
\hline Diabetic (4) & $85.9 \pm 1.10$ & $1.6 \pm 0.39$ & $10.1 \pm 0.89$ & $0.6 \pm 0.13$ & $1.9 \pm 0.29$ & $104(588977)$ & $44.6 \pm 6.73$ & $67.9 \pm 5.56$ \\
\hline
\end{tabular}

${ }^{a}$ Diameters were calculated as described by Miller and Small [26]. The volumes calculated from the diameters of the spherical particles are given in parentheses to assist with some of the comparisons described in the text. Measurements were made 3 weeks after injection of streptozotocin (diabetic) or citrate

$0.5 \mathrm{~cm}$ of the tube. Particles as small as $35 \mathrm{~nm}$ in diameter were recovered by this procedure, considerably smaller than the usual $70 \mathrm{~nm}$ cut-off for chylomicrons. The triglyceride-rich lipoproteins obtained were analysed for apoB48 and lipid contents. In 12 fasted rats $96.3 \pm 1.15 \%$ of total lymph apoB 48 was present in the top $0.5 \mathrm{~cm}$ fraction of the gradient. In 14 rats infused with Intralipid $98.8 \pm 0.25 \%$ of apoB 48 was present in this fraction. ApoB100 was not detected by SDS-PAGE in this fraction in any sample.

\section{Preparation of Intralipid containing cholesterol}

Intralipid (Vitrum AB, Stockholm, Sweden) has the composition soybean oil $(20 \% \mathrm{w} / \mathrm{v})$, egg phospholipid $(1.2 \% \mathrm{w} / \mathrm{v})$, and glycerol $(2.25 \% \mathrm{w} / \mathrm{v})$ emulsified into a heterogeneous mixture of particles ranging in diameter from 100 to $800 \mathrm{~nm}$ [21]. To prepare Intralipid with $2 \%$ cholesterol, Intralipid containing $196 \mathrm{mg}$ of triglyceride was dispensed into vials containing $4 \mathrm{mg}$ cholesterol and sonicated to incorporate the cholesterol into the emulsion particles. The lipids were sonicated in $8.5 \mathrm{ml}$ of $0.15 \mathrm{~mol} / \mathrm{l} \mathrm{NaCl}, 10 \mathrm{mmol} / / \mathrm{N}$-[2-hydroxyethyl] piperazine-N'[2-ethanesulphonic acid] $\mathrm{pH} 7.4$ at $55-56^{\circ} \mathrm{C}$ (monitored by a thermocouple in the vessel) with the atmosphere above the mixture purged with nitrogen to prevent lipid oxidation. Sonication was for 20 min using a $1 \mathrm{~cm}$ probe at a continuous output of 90-110 W with a Vibra-Cell high intensity ultrasonic processor (Sonics and Materials Inc., Danbury, Conn., USA). The lipid mixture was then centrifuged at $3000 \mathrm{rev} / \mathrm{min}$ for $1 \mathrm{~h}$ to remove titanium debris. buffer (controls). Results are given as mean \pm SEM, with numbers of rats in each group given in parentheses. To avoid clutter in the table, significant differences are not indicated, but the outcomes of analysis of variance of the effects due to dose, cholesterol and diabetes are described in the Results

\section{Purification of apoB 48}

Lymph chylomicrons were delipidated according to Herbert et al. [22]. Of the chylomicron suspension $10 \mathrm{ml}$ were mixed with $40 \mathrm{ml}$ of chloroform/methanol/ether 1:2:1 (by volume). After standing $1 \mathrm{~h}$ at $-20^{\circ} \mathrm{C}$ the precipitated proteins were pelletted by centrifugation for $30 \mathrm{~min}$ at $4^{\circ} \mathrm{C}$. The protein pellet was resuspended in a mixture of ether/methanol $2: 1(\mathrm{v} / \mathrm{v})$ at $-20^{\circ} \mathrm{C}$, centrifuged as before, and then resuspended and recentrifuged twice more in ether. Ether was then evaporated under a stream of nitrogen and the moist protein pellet was dissolved in buffer containing $2 \% \mathrm{SDS}$ and $0.1 \mathrm{~mol} / \mathrm{l}$ sodium phosphate $\mathrm{pH} 7.0$ at a concentration of $2 \mathrm{mg} / \mathrm{ml}$. Approximately $20 \mathrm{mg}$ of protein was applied to a $2.2 \times 80 \mathrm{~cm}$ column packed with Sepharose CL-6B as described by Hardman and Kane [23], eluted at room temperature with buffer containing $0.1 \% \mathrm{SDS}, 0.05 \% \mathrm{NaN}_{3}, 0.05 \%$ EDTA, $0.025 \mathrm{~mol} / \mathrm{/}$ sodium phosphate, $\mathrm{pH} 7.0$, at a flow rate of $30 \mathrm{ml} / \mathrm{h}$. Under these conditions apoB 48 eluted close to the void volume. Fractions containing apoB48 were pooled and concentrated by vacuum dialysis. Purified apoB 48 was shown to contain a single homogeneous band corresponding to apoB48 by SDSPAGE according to Laemmli [24].

\section{Quantitation of apoB48}

Lymph chylomicrons were partially delipidated by mixing $0.5 \mathrm{ml}$ of sample with $3 \mathrm{ml}$ of ether. After pelletting by centrifugation at $4^{\circ} \mathrm{C}$, residual ether was evaporated under a stream of nitrogen. Samples in a volume of $50 \mu 1$ were mixed with $50 \mu 1$ of reducing buffer $(0.01 \mathrm{~mol} / \mathrm{l}$ Tris-HCl, $\mathrm{pH} 6.8,1 \% \mathrm{SDS}, 0.04 \mathrm{~mol} / \mathrm{l}$ dithiothreitol) and $0.02 \%(\mathrm{w} / \mathrm{v})$ bromophenol blue and applied to a $4 \%$ 


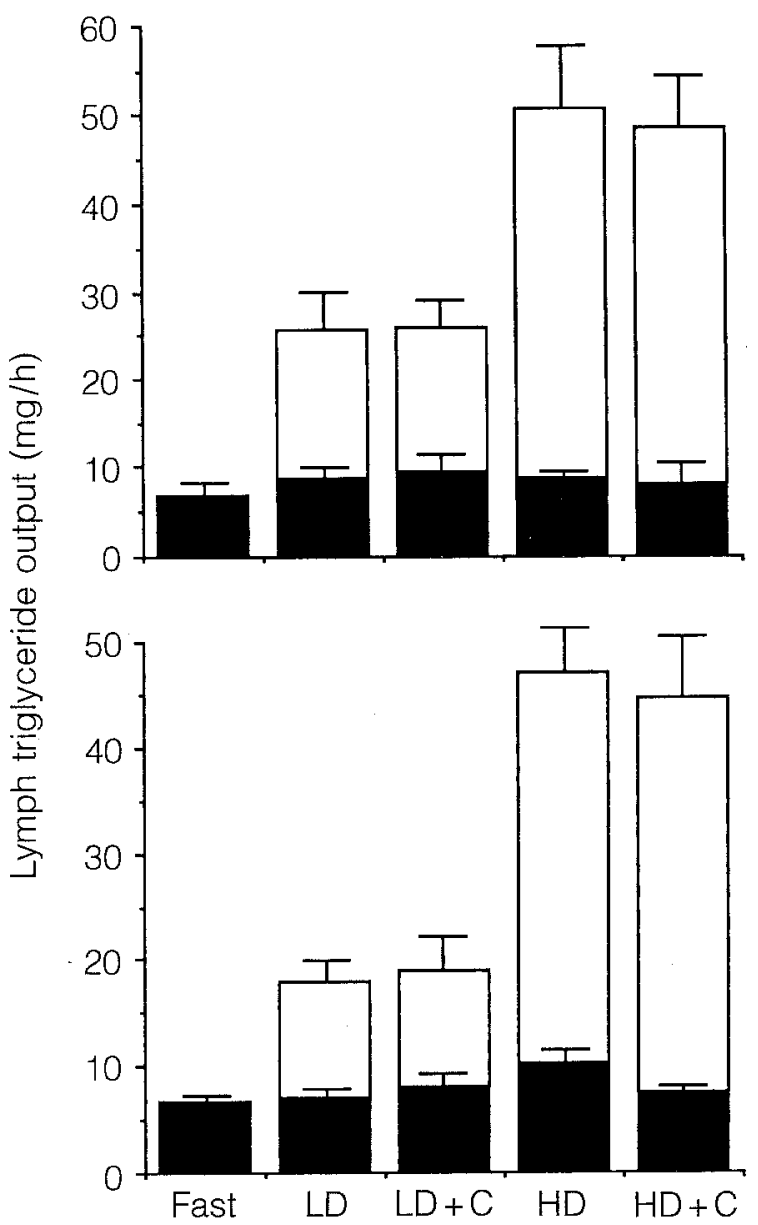

Fig.1. Transport of triglyceride in mesenteric lymph from (upper panel) control and (lower panel) diabetic rats. Data are shown from fasted rats, from rats during absorption of Intralipid at the lower dose or with and without cholesterol (LD $+C$ and $\mathrm{LD}$, respectively), and from rats during absorption of Intralipid at the higher dose or with and without cholesterol (HD $+\mathrm{C}$ and HD, respectively). Total transport is indicated by the open bars plus the solid bars. The solid bars show the amounts of transport that could be accommodated solely by the increases in apoB 48 , a measure of particle number, if particle size and composition remained unchanged. The open bars therefore represent the excess transport required to accommodate the actual transport, therefore reflecting increased particle volumes. The bars indicate 1 SEM of the plotted mean values, calculated from the data of Table 1

stacking gel that overlayed a 5-25\% vertical slab SDS-polyacrylamide gel $1.5 \mathrm{~mm}$ in thickness. A set of standards containing $2-$ $8 \mu \mathrm{g}$ of pure apoB 48 protein in duplicate were also applied to each gel. A poB 48 was assayed by the Lowry procedure using bovine serum albumin as a standard, corrected by $13 \%$ to account for greater chromogenicity of apoB48 [25]. Electrophoresis was for $4 \mathrm{~h}$ at constant current of $30 \mathrm{~mA}$ per gel in $0.025 \mathrm{~mol} / \mathrm{l}$ Tris, $0.092 \mathrm{~mol} / 1$ glycine, $0.1 \%$ SDS (pH 8.8). Gels were stained for $5 \mathrm{~h}$ in $1 \%(\mathrm{w} / \mathrm{v})$ Coomassie Brilliant Blue R-250 in methanol/acetic acid/water, (5/2/5 by volume), and destained in acetic acid/isopropanol/water ( $1 / 2 / 7$ by volume). The gels were imaged using an Epson Scanner 4000, and the image was analysed by a computerized Scan Analysis program (Biosoft, Milltown, NJ, USA). The absorbance of individual apoB48 bands was determined with subtraction of background absorbance from an ad- jacent similar sized area of gel. There was a linear relationship between the amounts of pure apoB48 standards applied to the gel and the absorbances determined by this procedure.

\section{Calculations of particle diameters and numbers in lymph}

Two different methods were used to estimate particle diameters and the numbers of chylomicron particles in each sample. In the first method the lipid compositions of the lymph chylomicrons were used to calculate the diameter of an average particle as described by Miller and Small [26]. The calculated mass of phospholipid in an average particle was then divided into the total mass of phospholipid to derive the number of particles in each sample. In the second method the numbers of particles in each sample were calculated from the measured apoB48 mass (g) by dividing by the apoB molecular weight and multiplying by Avogadro's number $\left(6.022 \times 10^{23}\right)$.

\section{Chemical analysis}

The lipids extracted from chylomicrons with chloroform-methanol $(2: 1 \mathrm{v} / \mathrm{v})$ were separated by thin layer chromatography on $0.2 \mathrm{~mm}$ layers of silica gel in the solvent system petroleum ether $40-60^{\circ} \mathrm{C} /$ diethyl ether/formic acid $(90 / 10 / 1$ by volume $)$. The triacylglycerol, cholesteryl ester and non-esterified cholesterol bands were scraped from the plate for assay of triacylglycerol by the chromotropic acid method [27], and non-esterified and esterified cholesterol by the $o$-phthaldialdehyde procedure [28]. Protein assay was by the procedure of Lowry et al. [29] with extraction of turbidity due to lipids with chloroform. Phospholipid was measured directly on chylomicron samples [30].

\section{Statistical analysis}

The data were compared by single classification and two-way analysis of variance, using Tukey's test for comparisons of individuals means. Comparisons of procedures for assessing numbers of particles were by paired $t$-tests. The significance of correlations was assessed using Bonferroni corrections [31].

\section{Results}

\section{Effects of the infused fat load}

Table 1 shows that the transport of triglyceride in lymph triglyceride-rich lipoproteins increased as the infused dose of Intralipid was increased $(p<0.001$ by analysis of variance). As triglyceride transport increased from $6 \mathrm{mg} / \mathrm{h}$ in fasted rats to about $40 \mathrm{mg} / \mathrm{h}$ at the higher dose of Intralipid, there was an increase in the triglyceride content of chylomicrons and a decrease in phospholipid content, consistent with the increase in chylomicron size that was also indicated by the calculated particle diameters. The data for control rats without cholesterol indicate that the volume of an average chylomicron particle increased 3.7-fold at the lower dose of Intralipid and 13.8-fold at the higher dose of Intralipid compared with fasted rats. With cholesterol in 
the infusate, the apparent increases in chylomicron volume were greater, at 9.9-fold and 28.4-fold respectively.

Compared with fasted rats, apoB48 transport during absorption of Intralipid increased significantly ( $p<0.025$ by analysis of variance) by about 1.5 -fold both with and without cholesterol in the infusate and with no significant differences between the lower and higher doses of Intralipid. The correlation between triglyceride transport and apoB 48 transport was weak $\left(r^{2}=0.17, p<0.001\right)$.

The data for transport of triglyceride in lymph are plotted in Figure 1. The amounts of transport that could be accommodated solely by the increases in apoB48, without increases in particle volume were calculated. By analysis of variance there were no significant effects on this parameter due to diabetes or to the infused dose of Intralipid. The excess transport was therefore due to increases in particle volumes, i.e. increases in the amount of triglyceride in the average lipoprotein particle. By analysis of variance the excess transport reflecting increased particle volume was significantly affected by the infused dose of Intralipid $(p<0.001)$ but not by diabetes or cholesterol in the infusate. The excess transport reflecting increased particle volume was highly correlated with total triglyceride transport in the lymph $\left(r^{2}=0.97, p<0.001\right)$.

The compositions of the lymph triglyceride-rich lipoproteins changed as the transported load of lipid increased. As expected the triglyceride contents increased and phospholipid contents decreased, reflecting the increase in particle diameters with increased load. Table 1 shows that as lipid load increased the relative contents of cholesterol, cholesteryl ester and total protein decreased. In contrast there were no significant correlations of apoB48 transport with any aspect of particle composition. The contents of cholesterol and cholesteryl ester were highly correlated $\left(r^{2}=\right.$ $0.88, p<0.005)$.

\section{Effects of cholesterol transport}

The increases in chylomicron volume when cholesterol was present in the infusate were noted above. Cholesterol transport had no significant effects on lymph triglyceride transport or apoB 48 transport, as shown by the data of Table 1 . The composition of chylomicrons was significantly affected by cholesterol in the infusate, not only with respect to the increased contents of cholesteryl esters and (to a lesser extent) cholesterol, but also to the decreased contents of phospholipids.

\section{Effects of diabetes}

As shown by the data of Table 1 , diabetes had no consistent or significant effects on lymph triglyceride transport or apoB48 transport. Chylomicron size was smal-
Table 2. The numbers per hour of triglyceride-rich lipoproteins in lymph calculated from particle compositions and the transport of apoB 48

\begin{tabular}{lll}
\hline & \multicolumn{2}{c}{ Particle numbers $\left(\times 10^{-14} / \mathrm{h}\right)$} \\
\cline { 2 - 3 } & $\begin{array}{l}\text { From particle } \\
\text { composition }^{\mathrm{a}}\end{array}$ & $\begin{array}{l}\text { From apoB48 } \\
\text { transport }^{\mathrm{b}}\end{array}$ \\
\hline Fasted & $2.82 \pm 0.64$ & $1.49 \pm 0.40$ \\
Control (8) & $2.41 \pm 0.32$ & $1.42 \pm 0.13$ \\
Diabetic (8) & & \\
Low dose Intralipid & & $1.95 \pm 0.31$ \\
Without cholesterol & $2.79 \pm 1.12$ & $1.58 \pm 0.19$ \\
Control (4) & $2.34 \pm 0.52$ & $2.04 \pm 0.39$ \\
Diabetic (4) & & $1.82 \pm 0.31$ \\
With cholesterol & $0.95 \pm 0.09$ & \\
Control (4) & $1.17 \pm 0.40$ & $1.96 \pm 0.08$ \\
Diabetic (4) & & $2.28 \pm 0.35$ \\
High dose Intralipid & & \\
Without cholesterol & $1.33 \pm 0.47$ & $1.81 \pm 0.49$ \\
Control (4) & & $1.69 \pm 0.14$ \\
Diabetic (4) & & \\
With cholesterol & & \\
Control (4) & & \\
Diabetic (4) & $0.81 \pm 0.41$ & \\
\hline
\end{tabular}

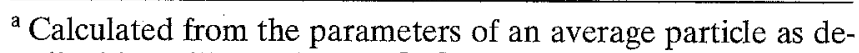
scribed by Miller and Small [26], by dividing the phospholipid content of an average particle into the hourly particle phospholipid output.

${ }^{b}$ Calculated as described in Materials and methods, assuming a single copy of apoB48 per particle. Measurements were made 3 weeks after injection of streptozotocin (diabetic) or citrate buffer (controls).

Results are given as mean \pm SEM, with numbers of rats in each group given in parentheses

Table 3. Body weights and plasma insulin, glucose and lipid concentrations in control and diabetic rats

\begin{tabular}{|c|c|c|c|}
\hline & \multirow{2}{*}{$\begin{array}{l}\text { Control } \\
\text { rats } \\
(8)\end{array}$} & \multicolumn{2}{|l|}{ Diabetic rats } \\
\hline & & $\begin{array}{l}\text { Fed ad-libitum } \\
(12)\end{array}$ & $\begin{array}{l}\text { Pair-fed } \\
(10)\end{array}$ \\
\hline $\begin{array}{l}\text { Food intake } \\
\text { (g/day) }\end{array}$ & $20.2 \pm 0.6$ & $31.6 \pm 0.9^{\mathrm{a}}$ & 20 \\
\hline $\begin{array}{l}\text { Body weight } \\
\text { (g) }\end{array}$ & $310 \pm 5$ & $252 \pm 6^{a}$ & $206 \pm 8^{a, e}$ \\
\hline $\begin{array}{l}\text { Plasma insulin } \\
(\mu \mathrm{U} / \mathrm{ml})\end{array}$ & $34.8 \pm 6.1$ & $6.1 \pm 0.8^{a}$ & $9.3 \pm 2.1^{\mathrm{a}}$ \\
\hline $\begin{array}{l}\text { Plasma glucose } \\
(\mathrm{mmol} / \mathrm{l})\end{array}$ & $7.5 \pm 0.56$ & $25.7 \pm 1.23^{a}$ & $16.1 \pm 1.17^{\mathrm{a}, \mathrm{e}}$ \\
\hline $\begin{array}{l}\text { Plasma triglyceride } \\
(\mathrm{mmol} / \mathrm{l})\end{array}$ & $1.0 \pm 0.19$ & $2.2 \pm 0.27^{\mathrm{b}}$ & $0.9 \pm 0.10^{d}$ \\
\hline $\begin{array}{l}\text { Plasma cholesterol } \\
(\mathrm{mmol} / \mathrm{l})\end{array}$ & $2.0 \pm 0.08$ & $2.3 \pm 0.10^{\circ}$ & $1.8 \pm 0.08^{\mathrm{d}}$ \\
\hline
\end{tabular}

Measurements were made 3 weeks after injection of streptozotocin (diabetic) or citrate buffer (controls). Results are given as mean $\pm \mathrm{SEM}$, with numbers of rats in each group given in parentheses. Mean body weight for all rats at the start of the study was $188 \pm 1 \mathrm{~g}$.

${ }^{\mathrm{a}} p<0.001,{ }^{\mathrm{b}} p<0.01,{ }^{\mathrm{c}} p<0.025$ vs control group;

${ }^{\mathrm{d}} p<0.001,{ }^{\mathrm{e}} p<0.01$ vs group fed ad libitum 
ler than in non-diabetic controls with and without cholesterol at both doses of Intralipid. In fasted rats the chylomicrons from diabetic rats contained significantly less cholesteryl esters than controls. Chylomicrons from fasted diabetic rats contained significantly less total protein than controls, but this trend disappeared during absorption of Intralipid.

\section{Calculations of numbers of chylomicrons during fat absorption}

Table 2 shows the numbers of chylomicron particles calculated by two procedures as described in the Materials and methods. Comparing the data calculated by the two methods there was no significant difference by paired $t$-test $(p>0.4, d f=47)$. It should be noted that if each particle contained two molecules of apoB48, the numbers of particles calculated from apoB 48 transport would be halved.

\section{Role of hyperphagia in chylomicron clearance in diabetes}

Abnormal clearance of chylomicrons occurs in insulindeficient rats fed ad libitum [14]. The hyperphagia of diabetic rats fed ad libitum may affect the clearance of chylomicrons from plasma by influencing the composition of triglyceride-rich lipoproteins of intestinal lymph, or by changing the physiological mechanisms responsible for clearance. To control for the first possibility, chylomicron-like emulsions free of exogenous apolipoproteins were used to assess chylomicron clearance. The plasma clearance of the chylomicron-like emulsions is comparable to lymph chylomicrons [32]. A group of diabetic rats fed ad libitum was compared with a group pair-fed with matched non-diabetic control rats.

Table 3 shows the plasma glucose was significantly increased in both groups of diabetic rats, but lower in pair-fed rats than those fed ad libitum. Plasma insulin was decreased in the diabetic groups and was not affected by pair-feeding. Both groups of diabetic rats gained less weight than the control group, and the pairfed rats gained less than diabetic rats fed ad libitum. Plasma triglycerides and cholesterol were significantly increased in diabetic rats fed ad libitum. However, in the pair-fed diabetic rats the plasma lipids were not significantly different from the control group.

Figure 2 shows the patterns of clearance from the plasma when radiolabelled chylomicron-like emulsions were injected into the three groups of rats. Consistent with previous findings from our laboratory [14], in rats fed ad libitum the clearances of both triolein and cholesteryl oleate labels were slower than in control rats. In the pair-fed diabetic rats the clearance of triolein was slightly faster than in the diabetic rats fed ad

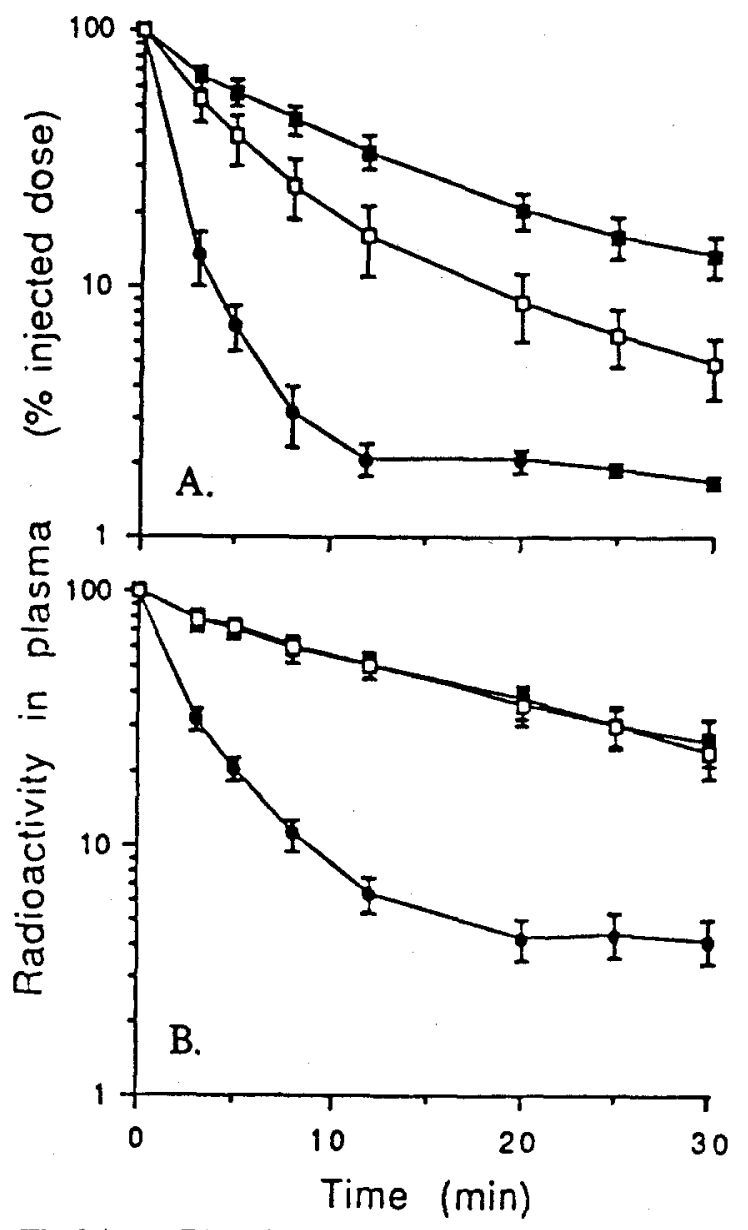

Fig.2A,B. The plasma clearances of chylomicron-like emulsions injected in control rats ( $)$ and streptozotocin-treated insulin-deficient diabetic rats fed ad libitum ( $)$ or pair-fed with control rats $(\square)$. The slow plasma clearance of triolein label, an index of lipolysis and particle clearance, was much slower in diabetic rats and was slightly improved but not restored to control values by pair-feeding (A). The slow plasma clearance of cholesteryl ester label, tracing particle remnants, was much slower in diabetic rats and was unaffected by pair-feeding $(\mathbf{B})$. Plotted are mean \pm SEM from the rats described in Table 4

Table 4. Half-lives of plasma clearance of radiolabelled triolein and cholesteryl oleate from chylomicron-like emulsions injected in control and pair-fed and ad libitum-fed diabetic rats

\begin{tabular}{|c|c|c|c|}
\hline & \multirow{2}{*}{$\begin{array}{l}\text { Control } \\
\text { rats } \\
(10)\end{array}$} & \multicolumn{2}{|l|}{ Diabetic rats } \\
\hline 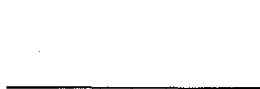 & & $\begin{array}{l}\text { Fed ad-libitum } \\
(12)\end{array}$ & $\begin{array}{l}\text { Pair-fed } \\
(8)\end{array}$ \\
\hline $\begin{array}{l}\text { Triolein } \\
\text { (min) }\end{array}$ & $2.9 \pm 0.4$ & $11.5 \pm 2.3^{\mathrm{a}}$ & $5.3 \pm 0.7^{\mathrm{a}, \mathrm{c}}$ \\
\hline $\begin{array}{l}\text { Cholesteryl oleate } \\
\text { (min) }\end{array}$ & $3.5 \pm 0.3$ & $17.6 \pm 3.6^{\mathrm{a}}$ & $19.5 \pm 3.9^{\mathrm{a}, \mathrm{b}}$ \\
\hline
\end{tabular}

Clearances of emulsion lipids were measured 3 weeks after in jection of streptozotocin (diabetic) or citrate buffer (controls). Results are given as mean \pm SEM, with numbers of rats in each group given in parentheses. The half-lives were calculated from the radioactivity remaining in the plasma 3-12 min after injection of emulsions in the groups of rats depicted in Figure 2.

${ }^{\mathrm{a}} p<0.01,{ }^{\mathrm{b}} p<0.001$ vs control group;

${ }^{c} p<0.05$ vs group fed ad libitum 
libitum, but remained slower than in non-diabetic controls. The clearance of cholesteryl oleate, which traces the plasma removal of remnant particles, was unchanged in pair-fed diabetic rats compared with the diabetic rats fed ad libitum.

The half-lives calculated from the data of Figure 2 are shown in Table 4. Compared with controls, in diabetic rats fed ad libitum the half-lives of clearances of emulsion triolein and cholesteryl oleate were significantly longer $(p<0.01)$. In pair-fed diabetic rats the half-life of emulsion triolein clearance was less than in diabetic rats fed ad libitum, but still significantly longer than in control rats $(p<0.05)$. However the prolonged clearance half-life of emulsion cholesteryl oleate, a marker for lipoprotein remnant clearance, was unaffected by pair-feeding.

\section{Discussion}

Reasons for the impairment of plasma clearance of triglyceride-rich lipoproteins in insulin-deficient rats are elusive. The likelihood that postprandial lipoproteins play a role in atherogenesis focuses attention on this problem in diabetes. While changes in intestinal handling of lipids are clearly documented, it is not clear that these changes impinge on the subsequent metabolism of chylomicrons. Our data indicate that insulin deficiency in rats has no effect on the transport of triglycerides or apoB48 in postprandial lymph. In diabetic rats as in controls, the increased lipid transport is accomplished mostly by increased particle volumes, with only small increases in numbers of particles in intestinal lymph.

In addition to our previous work describing the defect in chylomicron clearance in diabetic rats $[14,33$, 34], a number of other laboratories have reported similar findings [35-37]. Altogether defects have been found in the clearance of pre-formed remnants, as well as in clearance of intact lymph chylomicrons and of emulsion models of chylomicrons. In diabetic rats the emulsion models are robust tools since the necessity of injecting exogenous apolipoproteins, which could confound interpretations is avoided. Recently Staprans et al. [38] were unable to confirm the defect in clearance reported by us and others. Inspection of the data of Staprans et al. [38] does not entirely support their interpretation, however. In particular at $10 \mathrm{~min}$ post-injection their data show less uptake of chylomicron cholesterol in the liver, confirming the previous findings of Redgrave and Snibson [33]. The strategy of Staprans et al. [38] in injecting large doses of chylomicrons seems to prevent meaningful interpretation in terms of tracing the physiological events of interest. Ideally the tracer should be of the smallest possible quantity to avoid perturbation of the existing pool. It is possible that the large dose of non-diabetic apolipoproteins injected with normal chylomicrons was sufficient to correct a defect in the diabetic recipients.

In insulin-deficiency the intestine shows adaptive changes in response to hyperphagia, but our results indicate that prevention of hyperphagia did not overcome the impairment of the plasma clearance of chylomicron-like emulsions. It is noteworthy that plasma clearance of chylomicron-like emulsions was impaired despite the normalization of plasma lipid concentrations by prevention of hyperphagia. Dissociation of the clearance of chylomicron-like emulsions from the pool-size of plasma lipids has important implications in understanding the potential atherogenicity of chylomicron remnants in the context of normal concentrations of plasma lipids.

The data are consistent with the presence of only one apoB48 molecule per particle. By paired $t$-test there was no significant difference between the numbers calculated assuming a single apoB 48 molecule per particle and those calculated from particle composition. On the other hand the data were inconsistent with two molecules of apoB48 per particle, which would halve the numbers of particles. This finding contradicts earlier conclusions that two molecules of apoB48 may be present in chylomicrons [15]. Imprecision in assays and assumptions underlying the calculations contribute to the uncertainty of the estimations. With VLDL the problems of interpretation due to heterogeneity in particle size are less than with chylomicrons, and measurements indicate that hepatic VLDL contain a single molecule of apoB100 [16]. Parallel processes of assembly of the triglyeride-rich lipoproteins in enterocytes and hepatocytes are likely.

The output of apoB 48 increased by a small amount during Intralipid infusion compared with fasting. Consequently particle numbers calculated from the apoB 48 output also increased, averaging $33 \%$ overall for control and diabetic rats. The increase is unlikely to be due to an increased amount of apoB48 per particle. There were no significant effects due to cholesterol or diabetes.

During absorption of corn oil, olive oil and butter oil the cholesterol output in lymph chylomicrons was directly proportional to the amount of cholesterol infused into the intestine [39]. Our data in control and diabetic rats during Intralipid absorption with or without cholesterol also show a positive relationship between dietary cholesterol and chylomicron cholesterol. The decreased proportions of cholesterol and proteins in larger particles were consistent with their location in the lipoprotein surface as distinct from core, as the relative proportion of surface was less in larger particles. The relative decrease in content of cholesteryl esters in larger particles also suggested a surface location, and is concordant with previous observations [15] but not consistent with the presumed location of cholesteryl esters predominantly in the particle core. At the low concentration of cholesterol characteristic of 
lymph particles, $60 \%$ of fluorescent cholesteryl ester was in the surface of microemulsions, indicated by its accessibility to quenching agents [40].

The triglyceride-rich particles from lymph were as small as $35 \mathrm{~nm}$ in diameter and contained apoB48 but no apoB100. Our findings of small triglyceride-rich particles in lymph from fasted rats were supported by calculations based on particle compositions. Previously, measurements by electron microscopy showed particle diameters of $20-80 \mathrm{~nm}$ in fasting lymph, while after fat-feeding particle diameters ranged from less than $50 \mathrm{~nm}$ to more than $300 \mathrm{~nm}[19,41]$.

The mass of apoB output in the triglyceride-rich lipoproteins in lymph from fasted rats was about $55 \mu \mathrm{g} / \mathrm{h}$ increasing to about $75 \mu \mathrm{g} / \mathrm{h}$ during fat absorption. Our measurements gave numbers of particles in reasonable agreement with those calculated from particle compositions. Perhaps due to differences in strains of rats or for technical reasons, our measurements were smaller than those previously found by Krause et al. [42], who reported transport in lymph from fasted rats of about $140 \mu \mathrm{g} / \mathrm{h}$, increasing to about $200 \mu \mathrm{g} / \mathrm{h}$ in fat-fed rats. These values may be compared with measurements by immunoassay of about $140 \mu \mathrm{g} / \mathrm{h}$, with no changes between fasted and fat-fed rats [19]. ApoB48 was detected in fasting samples of human plasma [43, 44], consistent with a fasting production of intestinal particles in man also, since only the intestine produces apoB48 $[4,5]$. Therefore the transport of a lipid load in man also is most probably accomplished principally by increases in the size of particles rather than increases in particle numbers. This knowledge has implications for the interpretation of the plasma clearance of chylomicrons.

The findings of Tso et al. [41] provide further evidence for dissociation of lipid transport from the quantity of apoB48 in the intestinal lymph. Pluronic L81 inhibited the transport of triglyceride, but had no effect on the transport of apoB48. Conversely, triglyceride transport requires transport of apoB48, as Krause et al. [42] found that treatment of rats with ethinyl estradiol decreased lymph apoB48 transport by about $50 \%$ and inhibited the increase in triglyceride transport in postprandial intestinal lymph.

Insulin-deficiency changes a number of aspects of the handling of lipids by the intestine, some secondary to the associated hyperphagia and some independent of hyperphagia. Our present findings make it unlikely that the changes in intestinal function are directly responsible for changes in the subsequent plasma clearance of chylomicrons. In both control and diabetic rats increases in lipid transport were accomplished by increased particle size, with only small increases in numbers of particles in lymph. Restricted food intake in diabetic rats markedly decreased plasma triglycerides but still the clearance of chylomicron-like emulsion particles was slower. This result shows that the defect in clearance of chylomicron remnants is independent of hyperphagia, and exists in the presence of normal con- centrations of plasma triglycerides. It is likely that in diabetic rats changes in the association with chylomicrons of apoAIV, apoE isoforms or apoC's [14] or changes in endothelial lipases [45] or lipoprotein receptors are responsible for the defects in clearance of triacylglycerol-rich lipoproteins.

Acknowledgements. This work was funded by the National Health and Medical Research Council of Australia.

\section{References}

1. Chen S-H, Habib G, Yang CY et al. (1987) Apolipoprotein B-48 is the product of a messenger RNA with an organ-specific in-frame stop codon. Science 238: 363-366

2. Hodges P, Scott J (1992) Apolipoprotein B mRNA editing: a new tier for the control of gene expression. Trends Biochem Sci 17:77-81

3. Powell LM, Wallis SC, Pease RJ, Edwards YH, Knott TJ, Scott J (1987) A novel form of tissue specific RNA processing produces apo-B48 in intestine. Cell 50: 831-840

4. Glickman RM, Rogers M, Glickman JN (1986) Apolipoprotein $B$ synthesis by human liver and intestine in vitro. Proc Natl Acad Sci USA 83: 5296-5300

5. Hoeg JM, Sviridov DD, Tennyson GE et al. (1990) Both apolipoprotein B-48 and B-100 are synthesized and secreted by the human intestine. J Lipid Res 31: 1761-1769

6. Tennyson GE, Sabatos CA, Higuchi K, Meglin N, Brewer HB Jr (1989) Expression of apolipoprotein B mRNAs encoding higher- and lower-molecular weight isoproteins in rat liver and intestine. Proc Natl Acad Sci USA 86:500-504

7. Plump AS, Smith JD, Hayek Tet al. (1992) Severe hypercholesterolemia and atherosclerosis in apolipoprotein E-deficient mice created by homologous recombination in ES cells. Cell 71:343-353

8. Feingold KR (1989) Importance of small intestine in diabetic hypercholesterolemia. Diabetes 38: 141-145

9. Young NL, Lopez DR, McNamara DJ (1988) Contributions of absorbed dietary cholesterol and cholesterol synthesized in small intestine to hypercholesterolemia in diabetic rats. Diabetes 37: 1151-1156

10. Feingold KR, Zsigmond G, Lear SR, Moser AH (1986) Effect of food uptake on intestinal cholesterol synthesis in rats. Am J Physiol 251: G362-G369

11. Young NL, Saudek CD, Walters L, Lapeyrolerie J, Chang V (1982) Preventing hyperphagia normalizes 3-hydroxy-3methylglutaryl-CoA reductase activity in small intestine and liver of diabetic rats. J Lipid Res 23: 831-838

12. Jiao S, Matsuzawa Y, Matsubara K et al. (1988) Increased activity of intestinal acyl-CoA: cholesterol acyltransferase in rats with streptozotocin-induced diabetes and restoration by insulin supplementation. Diabetes 37:342-346

13. Matsubara K, Matsuzawa Y, Jiao S et al. (1988) Cholesterollowering effect of $\mathrm{N}-(\alpha$-methylbenzyl) linoleamide (melinamide) in cholesterol-fed diabetic rats. Atherosclerosis 72 : 199-204

14. Redgrave TG, Callow MJ (1990) The effect of insulin deficiency on the metabolism of lipid emulsion models of triacylglycerol-rich lipoproteins in rats. Metabolism 39: 1-10

15. Bhattacharya S, Redgrave TG (1981) The content of apolipoprotein B in chylomicron particles. J Lipid Res 22: $820-828$

16. Elovson J, Chatterton JE, Bell GT et al. (1988) Plasma very low density lipoproteins contain a single molecule of apolipoprotein B. J Lipid Res 29: 1461-1473 
17. Davidson NO, Kollner ME, Glickman RM (1986) Apolipoprotein $B$ synthesis in rat small intestine: regulation by dietary triglyceride and biliary lipid. J Lipid Res 27:30-39

18. Black DD, Rower-Nutter PL (1990) Intestinal apolipoprotein synthesis in the newborn piglet. Pediatr Res 29: 32-38

19. Hayashi H, Fujimoto K, Cardell JA, Nutting DF, Bergstedt S, Tso P (1990) Fat feeding increases size but not number of chylomicrons produced by small intestine. Am J Physiol 259: G709-G719

20. Redgrave TG, Roberts DCK, West CE (1975) Separation of plasma lipoproteins by density gradient ultracentrifugation. Anal Biochem 65: $42-49$

21. Schoefl GI (1968) The ultrastructure of chylomicra and of the particles in an artificial fat emulsion. Proc Roy Soc B 169: $147-152$

22. Herbert PN, Schulman RS, Levy RI, Fredrickson DS (1973) Fractionation of the C-apoproteins from human plasma very low density lipoproteins. J Biol Chem 248: 4941-4946

23. Hardman DA, Kane JP (1986) Isolation and characterization of apolipoprotein B48. In: Segrest JP, Albers JJ (eds) Methods in enzymology, plasma lipoproteins part A, Vol 128. Harcourt Brace Jovanovich, Orlando San Diego New York Austin London Montreal Sydney Tokyo Toronto, pp 262-272

24. Laemmli UK (1970) Cleavage of structural proteins during the assembly of the head of bacteriophage T4. Nature 227: 680-685

25. Zilversmit DB, Shea TM (1989) Quantitation of apo B-48 and apo B-100 by gel scanning or radio-iodination. J Lipid Res 30: 1639-1646

26. Miller KW, SmallDM (1987) Structure of triglyceride-rich lipoprotein: an analysis of core and surface phases. In: Gotto AM Jr (ed) Plasma lipoproteins. Elsevier, Amsterdam New York Oxford, pp 1-75

27. Carlson LA (1963) Determination of serum triglycerides. J Atheroscl Res 3: 333-336

28. Zlatkis A, Zak B (1969) Study of a new cholesterol reagent. Anal Biochem 29: 143-148

29. Lowry OH, Rosebrough NJ, Farr AL, Randall RJ (1951) Protein measurements with the Folin phenol reagent. J Biol Chem 193: 265-275

30. Barlett GR (1959) Phosphorus assay in column chromatography. J Biol Chem 234: 466-468

31. Wilkinson L, Hill MA, Vang E (1992) SYSTAT: statistics, Version 5.2 edition. SYSTAT, Inc., Evanston

32. Redgrave TG, Ly HL, Quintao E, Ramberg CF, Boston RC (1993) Clearance from plasma of triacylglycerol and cholesteryl ester after intravenous injection of chylomicron-like lipid emulsions in rats and man. Biochem J 290: 843-847

33. Redgrave TG, Snibson DA (1977) Clearance of chylomicron triacylglycerol and cholesteryl ester from the plasma of strep- tozotocin-induced diabetic and hypercholesterolemic hypothyroid rats. Metabolism 26: 493-503

34. Mamo JCL, Elsegood CL, Umeda Y, Hirano T, Redgrave TG (1993) Effect of Probucol on plasma clearance and organ uptake of chylomicrons and VLDLs in normal and diabetic rats. Arterioscl Thromb 13: 231-239

35. Levy E, Shafrir E, Ziv E et al. (1985) Composition, removal and metabolic fate of chylomicrons derived from diabetic rats. Biochim Biophys Acta 834: 376-385

36. Zerbinatti CV, Oliveira HCF, Wechesler S, Quintao ECR (1991) Independent regulation of chylomicron lipolysis and particle removal rates: effects of insulin and thyroid hormones on the metabolism of artificial chylomicrons. Metabolism 40: 1122-1127

37. Tetsu E, Tsutomu H, Mamo JCL et al. (1993) Hyperlipidemia in streptozotocin-diabetic hamsters as a model for human insulin-deficient diabetes: comparison with streptozotocindiabetic rats. Metabolism

38. Staprans I, Pan X-M, Rapp JH, Feingold KR (1992) Chylomicron and chylomicron remnant metabolism in STZ-induced diabetic rats. Diabetes 41:325-333

39. Kalogeris JJ, Story JA (1992) Lymph chylomicron composition and size are modified by level of intestinally infused cholesterol and triglyceride source in rats. J Nutr 122: 1045-1055

40. Li Q-T, Sawyer WH (1992) Effect of unesterified cholesterol on the compartmentation of a fluorescent cholesteryl ester in a lipoprotein-like lipid microemulsion. J Lipid Res 33: $503-512$

41. Tso P, Drake DS, Black DD, Sabesin SM (1984) Evidence for separate pathways of chylomicron and very low-density lipoprotein assembly and transport by rat small intestine. Am J Physiol 247: G559-G610

42. Krause BR, Sloop CH, Castle CK, Roheim PS (1981) Mesenteric lymph apolipoproteins in control and ethinyl estradioltreated rats: a model for studying apolipoproteins of intestinal origin. J Lipid Res 22: 610-619

43. Nestel PJ, Fidge NH, Tan MH (1982) Increased lipoproteinremnant formation in chronic renal failure. New Engl J Med 307: 329-333

44. Cohn JS, McNamara JR, Cohn SD, Ordovas JM, Schaefer EJ (1988) Plasma apolipoprotein changes in the triglyceriderich lipoprotein fraction of human subjects fed a fat-rich meal. J Lipid Res 29: 925-936

45. Mamo JCL, Hirano T, Sainsbury A, Fitzgerald AK, Redgrave TG (1992) Hypertriglyceridemia is exacerbated by slow lipolysis of triacylglycerol-rich lipoproteins in fed but not fasted streptozotocin diabetic rats. Biochim Biophys Acta 1128: 132-138 